\title{
Pembuatan Iklan Tanaman hias pada UB. Dika Flowers Berbasis Web dengan Metode Icing Device
}

\author{
${ }^{*}$ Ramli $^{1}$, Nur Wulan ${ }^{2}$, Joko Agung Harditriani ${ }^{3}$
}

Address: Universitas Harapan Medan/Fakultas Teknik dan Komputer, Program Studi D3 Manajemen Informatika, Indonesia ${ }^{1,2}$, Universitas Harapan Medan/FakultasTeknik dan Komputer, program Studi Teknik Informatika ${ }^{3}$

Email:ramli.brt@gmail.com, nurwulanstth@gmail.com, jokoagung_28@yahoo.com

* Corresponding author

\begin{abstract}
Abstrak
Saat ini banyak sekali jenis periklanan yang telah dilakukan oleh perusahaan untuk memasarkan produk mereka. Mulai dari periklanan yang ditampilkan di televisi, radio atau spanduk dan lain sebagainya. Namun untuk produk tanaman hias, banyak toko yang berada di tanjung morawa masih mengunakan sistem yang manual untuk memasarkan dan mengiklankan produk tanaman hias mereka, seperti hanya sekedar memasang spanduk-spanduk didepan toko atau outlet mereka. Hal inilah yang mungkin sekiranya perlu diubah dalam memasarkan produk agar lebih terjangkau lagi dengan masyarakat luas. Yaitu dengan memasang iklan berbasis website, dimana website ini dapat memasarkan produk-produk yang dibutuhkan oleh masyarakat, serta masyarakat pun diberi kemudahan dalam mendapatkan informasi yang dibutuhkan. Iklan aneka tanaman hias di UB.Dika Flowers ini pembuatannya memakai bahasa pemrograman php dan database mysql untuk penyimpanan dan pengolahan datanya. Dan website ini dibuat dengan metode periklanan, yaitu metode icing device dengan menggunakan kata-kata bijak / quotes mengenai tanaman tersebut. Dan tujuan pembuatan iklan aneka tanaman hias berbasis website ini adalah memperluas promosi serta penyampaian berbagai informasi mengenai aneka tanaman hias tersebut kepada para pelanggan/konsumen. Untuk memfasilitasi masyarakat dalam mengakses informasi iklan dan juga memfasilitasi perusahaan dalam mengiklankan produk mereka, agar pemasarannya lebih efektif dan efisien.
\end{abstract}

Kata Kunci : Iklan, Website, Tanaman Hias

\section{Latar Belakang}

Pada era globalisasi saat ini teknologi terus berkembang dan menyusup di semua sendi kehidupan manusia. Kebutuhan masyarakat akan informasi sangat meningkat seiring perkembangan teknologi dan informasi yang semakin pesat dan menghasilkan inovasi-inovasi baru yang senantiasa terus berubah kearah yang lebih baik. Kebutuhan tentang informasi menjadi hal yang sangat penting, karena informasi adalah konsep yang universal dalam jumlah muatan yang besar, meliputi banyak hal dalam ruang lingkupnya masing-masing dan terekam pada sejumlah media. Informasi merupakan data yang penting yang memberikan pengetahuan yang berguna.
Perkembangan dunia bisnis yang semakin pesat dan persaingaan usaha yang semakin ketat mendorong para pelaku usaha untuk meningkatkan kinerja perusahaanya. Teknologi komputer berkembang sangat pesat dengan munculnya internet dimana komputer-komputer dapat saling terhubung membentuk jaringan yang sangat luas di seluruh dunia. Siapapun yang mempunyai akses kedalam jaringannya dapat saling bertukar informasi berbagai macam bentuk data teks, gambar, suara, file dan sebagainya. Lebih dari itu jaringan ini dapat diakses selama 24 jam.

Internet merupakan media promosi atau informasi iklan yang bisa dibilang sangat murah dan menjadi peluang bisnis baru bagi 
toko, perusahaan, atau instansi maupun organisasi untuk memperluas pemasarannya. Untuk mencapai kebutuhan tersebut diperlukan sebuah situs web atau biasa disebut dengan website yang dinamis, menarik, dan up to date.

UB. Dika Flowers merupakan toko yang menjual berbagai macam aneka tanaman hias dan melayani jasa pertamanan. Selama ini promosi iklan yang dilakukan oleh Dika Flowers hanya memasarkan produk mereka dengan hanya memajang iklan (spanduk) didepan toko atau outlet mereka, dan juga hanya menggunakan brosur sehingga promosinya masih sangat terbatas, hanya daerah tanjung morawa sekitarnya dan informasinya kurang meluas hingga ke kotakota lainnya.

Untuk mengatasi masalah tersebut penulis membuat sebuah layanan iklan yang dapat diakses dengan cepat dan mudah yaitu iklan promosi tanaman hias berbasis website menggunakan bahasa pemrograman PHP dan database MySql sebagai tempat penyimpanan datanya. Penulisan artikel iklan promosi tanaman hias ini bertujuan untuk membuat media periklanan berbasis web yang user friendly dalam artian mudah dalam penggunaannya. Memperluas promosi iklan serta mengenalkan berbagai aneka tanaman hias dikalangan masyarakat menggunakan website dengan menggunakan kata-kata bijak / quotes mengenai tanaman tersebut dari Metode Icing device sehingga promosinya lebih menarik.

\section{Metode}

\section{Metode Icing Device}

Metode Icing Device (teknik tataan) adalah upaya menyusun pesan komunikasi sedemikian rupa sehingga enak didengar, atau enak dilihat atau enak dibaca dan orang memiliki kecenderungan untuk mengikuti apa yang disarankan oleh pesan tersebut. Komunikasi persuasif bertujuan untuk merubah sikap anggota yang tadinya kurang patuh menjadi patuh melaksanakan tugasnya.

$\begin{array}{ccr}\text { Teknik } & \text { tataan dalam } & \text { kegiatan } \\ \text { komunikasi } & \text { persuasif dengan } & \text { jalan } \\ \text { mengadakan } & \text { kebangkitan } & \text { emosi }\end{array}$
menggunakan (emotional appeal), adalah seni menata pesan dengan imbauan-imbauan sedemikian rupa sehingga menarik. Tentu semua mengetahui bahwa barang yang sama kualitasnya kadang-kadang bisa lebih menarik, apabila diberi bungkus yang lebih indah, etiket yang lebih baik, dan disajikan pada pajangan yang lebih menawan, dapat memberikan kesan yang tidak mudah dilupakan, lebih menonjol daripada yang lainlain.

Teknik icing device dapat dibedakan menjadi,

1. Teknik icing device menggunakan alat kata-kata bijak

2. Teknik icing device menggunakan alat analogi

3. Teknik icing device menggunakan alat cerita

4. Teknik icing device menggunakan alat humor

\section{Tahapan Penelitian}

Dalam penyelesaian tulisan ini dilakukan dengan beberapa tahapan kegiatan, antara lain:

1. Studi Pustaka

Dengan mencari informasi mengenai teori-teori yang berhubungan dengan penulisan artikel ilmiah, periklanan, komputer, teknologi informasi dan komunikasi, internet, wesite dan pengembangannya, tanaman hias, etode icing device dan pemrograman berbasis web dari berbagai sember sumber-sumber seperti buku, jurnal dan sumber lainnya.

2. Observasi

Dengan melaksanakan pengamatan atau pengambilan data langsung dilokasi penelitian. Dalam hal ini pengamatan dan pengambilan data secara langsung ke UB. Dika Flowers. Pengamatan dan pengambilan data disini, yakni melihat jenis-jenis tanaman dan melakukan pengambilan data dengan cara memfoto tanaman-tanaman tersebut sebagai bahan pembuatan iklan tersebut.

3. Wawancara

Melakukan tanya jawab langsung mengenai hal-hal yang berhubungan dengan penelitian. Dalam hal ini melakukan tanya jawab kepada Bapak Sumargianto selaku pemilik UB. Dika Flowers. Materi yang ditanyakan mengenai: informasi jenis tanaman, deskripsi / penjelasan tanaman serta harganya.

4. Perancangan Sistem

Merancang sistem yang diimplementasikan ke dalam komputer seperti: merancang tabel database, rancangan input, rancangan layar dan sebagainya.

5. Implementasi Sistem

Mengimplementasikan ke dalam bentuk program komputer. Penulisan kode program menggunakan PHP, MYSQL, HTML. 


\section{Hasil \\ Analisa Sistem}

UB.Dika Flowers merupakan toko yang menjual berbagai macam aneka tanaman hias dan melayani jasa pertamanan. Selama ini penyampaian promosi iklan tanaman hias yang dilakukan oleh UB.Dika Flowers adalah memasarkan produk mereka dengan memajang iklan (spanduk) didepan toko ataupun usaha mereka, dan juga menggunakan brosur sehingga promosinya masih sangat terbatas, hanya daerah tanjung morawa sekitarnya dan promosinya kurang meluas hingga ke kota-kota lainnya.

Pembuatan website pada UB.Dika Flowers ini bertujuan untuk memperluas iklan promosi dan memperkenalkan berbagai aneka tanaman hias yang ada di UB.Dika Flowers dengan menggunakan kata-kata bijak / quotes mengenai tanaman tersebut untuk membuat kualitas iklan promosi lebih menarik kepada para pelanggan / konsumen

\section{Analisis Kebutuhan Sistem.}

Analisis kebutuhan sistem sangat dibutuhkan untuk mendukung kinerja system dan tercapainya tujuan pembuatan sistem tersebut.

1. Perangkat Keras (Hardware)

Perangkat keras (Hardware) merupakan komponen yang sangat dibutuhkan dalam mewujudkan sistem yang diusulkan. Spesifikasi perangkat keras (hardware) yang dibutuhkan adalah:
a. Personel Computer dengan Processor min Intel Pentium Core 2 Duo
b. Harddisk $250 \mathrm{~GB}$
c. Monitor Super VGA
d. Memory min $64 \mathrm{MB}$

2. Perangkat Lunak (Software)

Perangkat lunak yang dibutuhkan untuk sistem yang dirancang adalah sebagai berikut :
a. Sistem Operasi
b. Adobe Dreamweaver CS3
c. Xampp
d. Browser

3. Pengguna (Brainware)

Setelah perangkat keras dan perangkat lunak ditentukan dalam hal ini Brainware atau sumber daya manusia itu sendiri juga penting dalam pembuatan sistem ini. Brainware adalah sumber daya manusia yang nantinya akan berperan sebagai user ataupun administrator sistem. Brainware yang dibutuhkan sebagai administrator nantinya bekerja pada server dalam pengolahan data website. Administrator harus mengerti tentang bahasa pemrograman PHP dan MySQL serta mengerti akan jalannya sistem. Sedangkan user tidak harus memiliki kemampuan khusus hanya saja mampu mengoperasikan internet browser.

\section{Perancangan Sistem}

Untuk mengatasi permasalahan di UB.Dika Flowers yang masih terbatasnya informasi kepada pelanggan, maka dirancang sistem promosi iklan dengan menggunakan media website. Dengan media Website yang dapat diakses dengan internet memiliki kemampuan menyampaikan informasi secara efisien dab efektif kepada konsumen serta memperluas jangkauan penyampaian iklan produk dan dengan menggunakan kata bijak / quotes dari Metode Icing Device mengenai tanaman di UB.Dika Flowers dapat membuat kualitas iklan promosi lebih menarik konsumen.

\section{Rancangan Use Case Diagram}

Use Case Diagram digunakan untuk menggambarkan fungsionalitas yang diharapkan dari sebuah sistem dan mendeskripsikan fungsi sebuah sistem dari sudut pandang pengguna sistem, dapat sangat membantu pada saat kita menyusun requirement sebuah sistem, mengkomunikasikannya dengan klien, dan merancang pengujian untuk semua fitur yang terdapat didalam sistem. Rancangan hasil analisa tersebut adalah sebagai berikut:

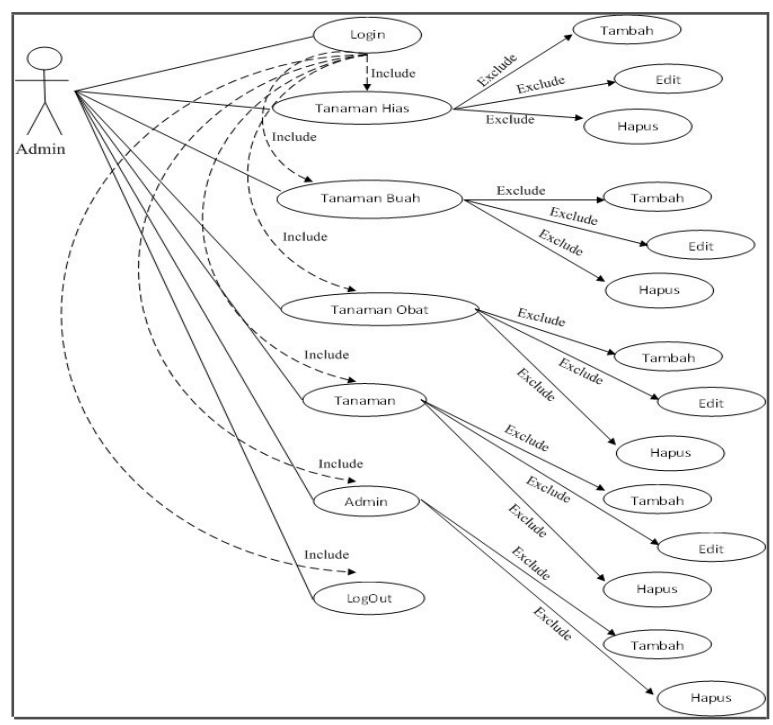

Gambar 1 Use Case Admin

Pada Gambar 1 Use Case Admin, menggambarkan admin yang merupakan pengguna sistem. Admin dapat login untuk 
melakukan proses merubah data, menambah data, hapus data, simpan data dan keluar.

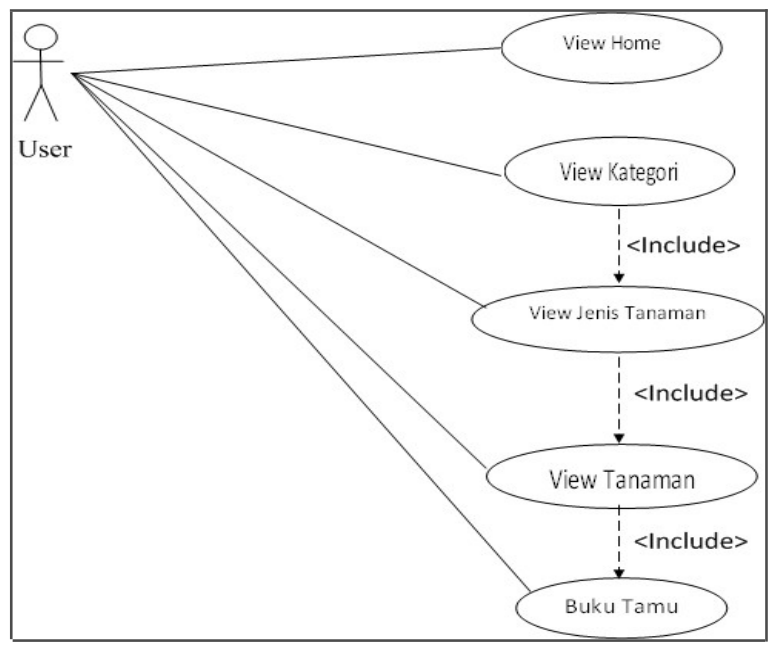

Gambar 2 Use Case User

Pada Gambar 2 Use Case User, menggambarkan sebagai user yang merupakan pengguna sistem iklan tanaman hias, melalui gambar use case user dapat melihat tampilan home awal, kategori jenis tanaman, jenis tanaman, dan informasi mengenai tanaman tersebut secara detail.

\section{Rancangan Layar}

Rancangan layari dibuat untuk memudahkan user mendapatkan informasi. Adapun rancangan layar tersebut adalah sebagai berikut:

1. Rancangan Layar Utama

Halaman utama didesain sedemikian rupa sehingga halaman ini dapat menyajikan ringkasan informasi yang informatif. Pada layar ini akan ditampilkan judul, dan beberapa link yang akan diakses. Tampilan Logo fb dan twitter dibawah yaitu link apabila kita ingin ke halaman $f b$ atau twitter.

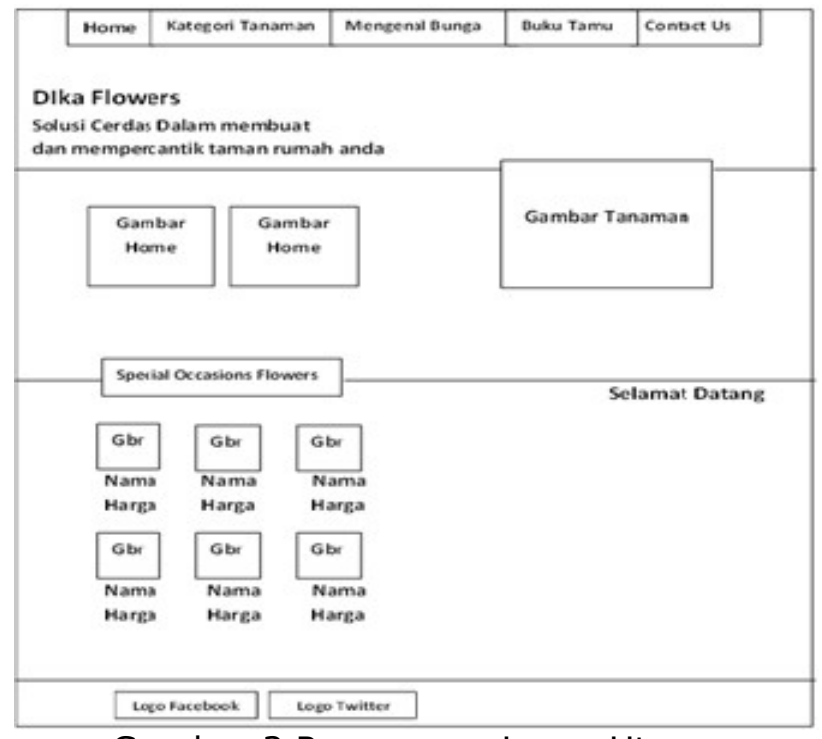

Gambar 3 Rancangan Layar Utama

2. Rancangan Layar Jenis Tanaman Rancangan layar ini menampilkan daftar tanaman disertai dengan informasi dan gambar sesuai dengan jenisnya

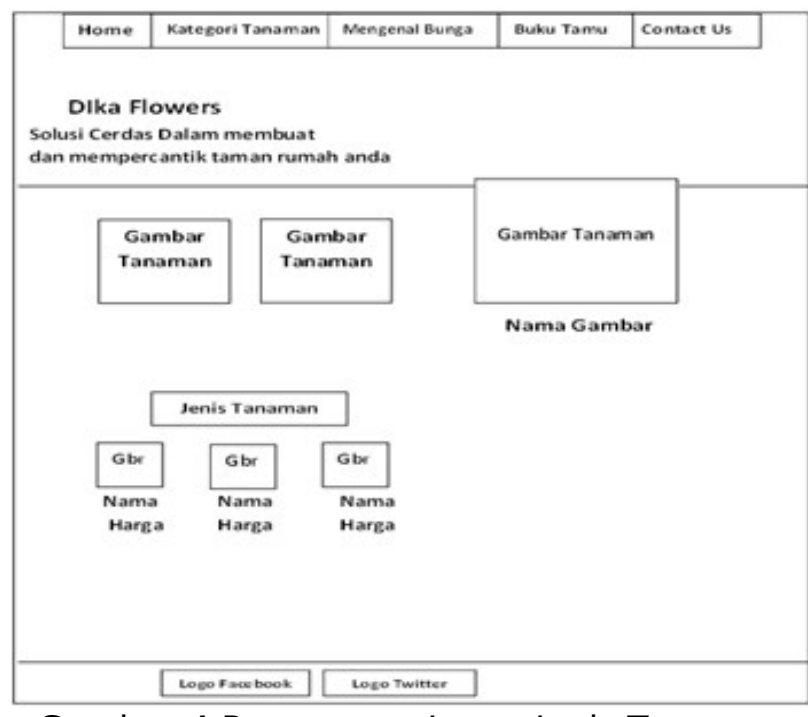

Gambar 4 Rancangan Layar Jenis Tanaman

3. Rancangan Layar Buku Tamu

Layar ini akan menampilkan daftar nama, email pengunjung dan pesan apabila pengunjung ingin memberikan kritik dan saran. 


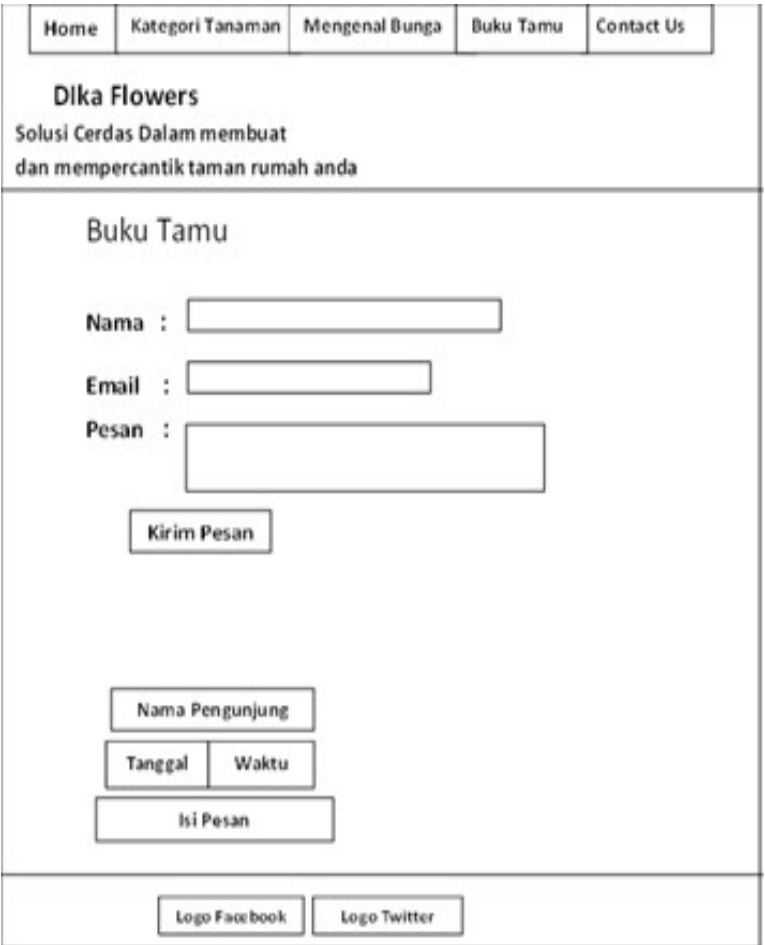

Gambar 5 Rancangan Layar Buku Tamu

\section{Rancangan Layar Admin}

Layar ini hanya bisa diakses setelah pengguna berhasil memasukkan username dan password dengan benar. Pada layar ini menampilkan statistik database, seperti tabel admin, tabel bunga, tabel image, tabel jenis tanaman, dan tabel kategori.

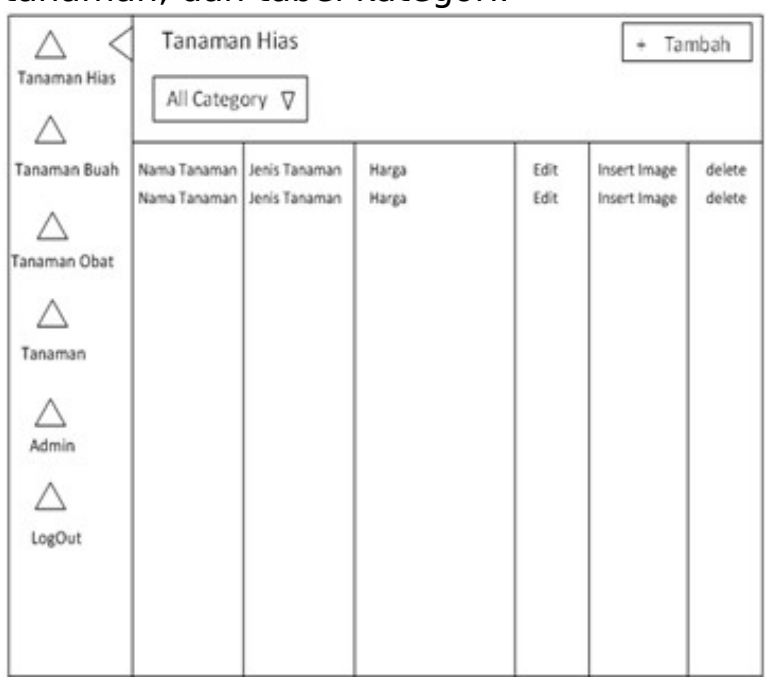

Gambar 5 Rancangan Layar Admin

5. Rancangan Layar Input Tanaman Hias Rancangan layar ini akan menampilkan jenis tanaman hias yang ingin di input, beserta nama tanaman hias, harga, kata bijak / quotes dan deskripsi.

Program Studi Teknik Informatika

Universitas Prima Indonesia (UNPRI) Medan

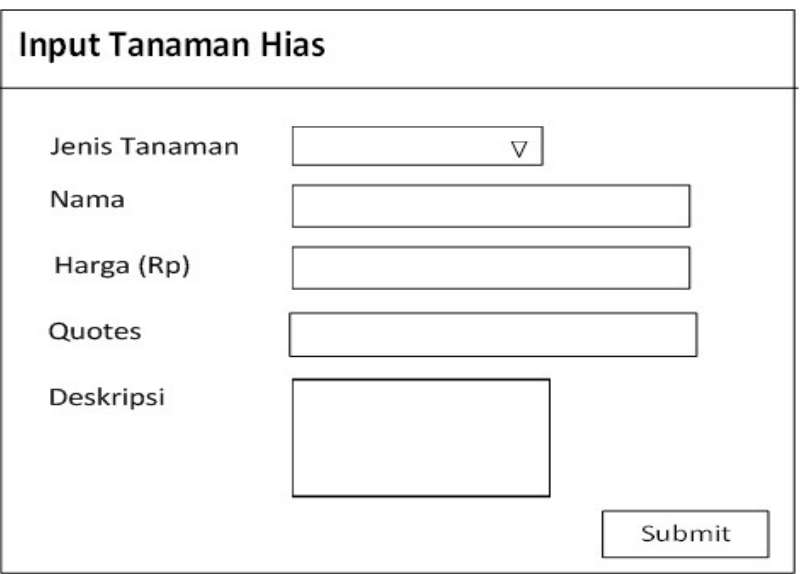

Gambar 6 Rancangan Layar Input Tanaman Hias

6. Rancangan Layar Input Tanaman Buah Rancangan layar ini akan menampilkan jenis tanaman buah yang ingin di input, beserta nama buah, harga, kata bijak / quotes dan deskripsi.

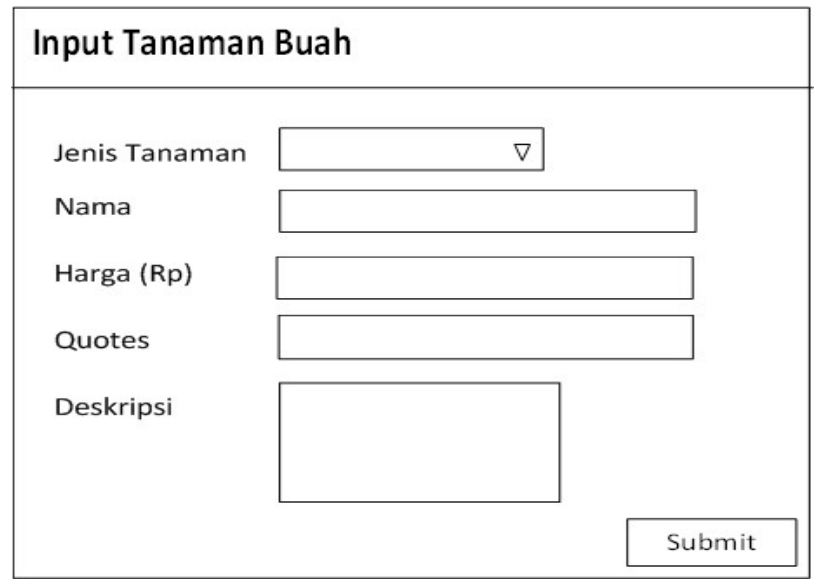

Gambar 7 Rancangan Layar Input Tanaman Buah

7. Rancangan Layar Input Tanaman Obat Rancangan layar ini akan menampilkan jenis tanaman obat yang ingin di input, beserta nama tanaman obat, harga, kata bijak / quotes dan deskripsi 


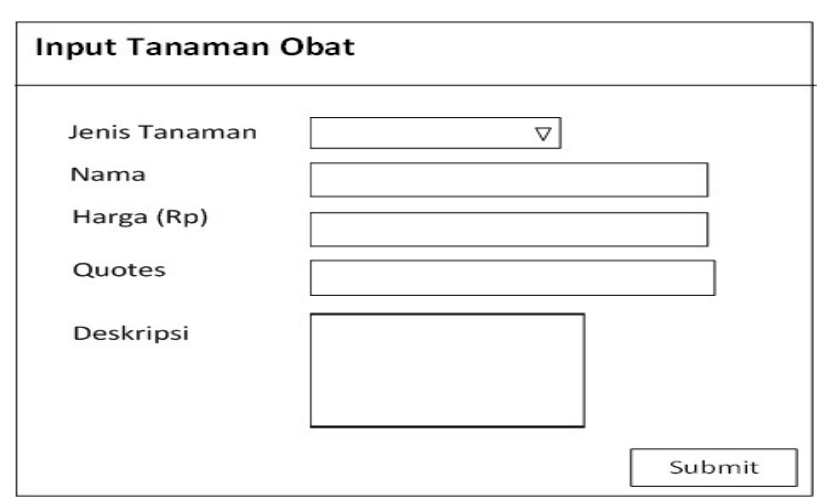

Gambar 8 Rancangan Layar Input Tanaman Obat

\section{Kesimpulan}

Sebagai hasil akhir dalam tulisan ini dapat disimpulkan:

1. UB.Dika Flowers selama ini dalam mempromosikan tanaman hiasnya dilakukan dengan cara memajang iklan (spanduk) di depan toko atau outlet mereka, menggunakan brosur dengan jangkauan yang terbatas

2. Untuk memudahkan dan memperluas jangkauan promosi tanaman hias tersebut dirancang media iklan promosi berbasis Web dengan menggunakan metode icing device

3. Dengan adanya Iklan promosi tanaman hias berbasis web pada UB.Dika Flowers ini maka informasi mengenai tanaman hias yang ada akan lebih mudah disampaikan kepada masyarakat luas dengan tidak dibatasi oleh waktu danjarak - selagi masih terjangkau oleh jaringan internet maka informasi dapat sampaikan.

4. Penyampaian iklan promosi produk dengan menggunakan kata bijak / quotes dari Metode Icing Device mengenai tanaman di UB.Dika Flowers untuk membuat kualitas promosi iklan lebih menarik terhadap pelanggan / konsumen.

5. Diharapkan kepada UB. Dika Flowers kedepannya dapat mengembangkan website ini menjadi toko online, agar dapat melakukan transaksi secara online.

\section{References}

1] Andi, "Mastering CMS Programming With $P H P \& M y$ SQ"L. Yogyakarta: Andi; Semarang: Wahana Komputer, 2011

[2] Andi, "Teknik Singkat Dan Cepat Menguasai CSS3". Yogyakarta: Andi; Semarang: Wahana Komputer, 2013.

[3] Nugroho, B. "Dasar Pemrograman Web PHP-MySQL Dengan Dreamweaver". Yogyakarta: Gava Media, 2013.

Program Studi Teknik Informatika

Universitas Prima Indonesia (UNPRI) Medan
[4] Oktavian, D, “Membuat Website Powerfull Menggunakan PHP". Yogyakarta: Mediakom, 2013.

[5] Sastrapradja, Setijati D, "Perjalanan Panjang Tanaman Indonesia". Jakarta: Yayasan Pustaka Obor Indonesia, 2012.

[6] Suyanto, M, "Strategi Periklanan pada eCommerce Perusahaan Top Dunia". Yogyakarta: Andi, 2003.

[7] Triwahyuni., et al. "Pesona 500 Jenis Tanaman Hias Bunga". Yogyakarta: Andi, 2010. 